\title{
Comparative Study on the Frequency and Wear of Thermoplastic Polymeric Materials Based on PTFE
}

\author{
IVONA CAMELIA PETRE ${ }^{1}$, ELENA VALENTINA STOIAN ${ }^{1 *}$, \\ MARIA CRISTIANA ENESCU ${ }^{1}$, CARMEN OTILIA RUSANESCU ${ }^{2 *}$ \\ ${ }^{1}$ Valahia University of Targoviste, Faculty of Materials Engineering and Mechanics, 13 Sinaia Alley, 130004, Targoviste, \\ Romania \\ ${ }^{2}$ Politehnica University of Bucharest, Faculty of Engineering of Biotechnical Systems, 313 Splaiul Independentei, 060042, \\ Bucharest, Romania
}

\begin{abstract}
The widespread use of thermoplastic polymeric materials in various industrial fields has shown considerable interest in understanding the frictional and wear behavior. Among these polymers, polytetrafluoroethylene, also called PTFE, is a high-performance plastic that offers high chemical and thermal resistance and low friction. Additives such as fiberglass, carbon and graphite fillers are added to PTFE to significantly increase thermal conductivity, stiffness and self-lubricating properties. The materials subjected to the experimental analysis were pure PTFE, PTFE $+15 \%$ fiberglass, PTFE + carbon-graphite which slipped, under conditions of dry friction, on a sample of non-alloy steel construction SR EN 10025 from 1994. The tests were performed on a pin-on-disc tribometer. The effect of loading and sliding speed on the tribological properties of the polymer / steel combination under dry slip conditions was investigated and the specific wear rate for the experimental conditions was evaluated. The tests were performed at loads of the pin of $F_{n 1}=1 N, F_{n 2}=3 N, F_{n 3}=5 N$ and $F_{n 4}=10 \mathrm{~N}$ and sliding speeds of $v_{1}=1 \mathrm{~m} / \mathrm{s}, v_{2}=3 \mathrm{~m} / \mathrm{s}$. The results obtained indicated that the coefficient of friction decreases with increasing load. The wear rate for the analyzed materials was between $10^{-13} \ldots 10^{-15} \mathrm{~m}^{2} / \mathrm{N}$, the fiberglass reinforced PTFE material having the lowest wear rate. The present paper, through a comparative analysis of the friction and wear behavior, highlights the effects that the ingredients introduced in the basic material have, under the action of the exploitation factors (loading, sliding speed).
\end{abstract}

Keywords: PTFE, friction, wear, tribological behavior, working parameters

\section{Introduction}

Numerous tribological research conducted for the coupling of metal / polymer materials was due to the fact that this pair of materials do not comply with the "friction laws" established for metal contacts in relative motion. The tribological peculiarities of polymeric materials are determined by their viscoelastic properties, by the low conductivities associated with the generation of heat in the frictional materials, by the melting points significantly lower than those of metals [1-6].

This is necessary because thermoplastic polymeric materials are increasingly used in industrial applications as metal substitutes, for the realization of various machine parts (bearings and bearing bushes, bearings, compression segments, and so on). They are characterized by a high strength / weight ratio, self-lubricating properties, good damping properties, high corrosion and temperature resistance and last but not least a low wear.

Throughout the technical-scientific evolution, the improvement of the technical-tribo-mechanical properties was permanently sought. Pure polymers, such as PTFE, add additives such as fiberglass, carbon and graphite fillers to improve tribo-mechanical properties [1]. In the literature $[1,7,8]$ it has been indicated that when polymers are reinforced with glass fibers, carbon, graphite the coefficient of friction can generally be reduced and the wear resistance improved.

\footnotetext{
*email: elenastoian22@gmail.com,rusanescuotilia@gmail.com
} 
In this context, in order to know the tribological behavior of the materials, numerous experimental researches are needed that correspond to the operating conditions of the friction torque. Following these analyzes, a much easier selection of the desired pair of materials for industrial applications can be made.

\section{Materials and methods}

\subsection{Choice of materials}

It is known that the friction and wear behavior of polymeric materials can be improved by adding special fillings to the base material, in order to give it a better behavior. at friction and wear, lower adhesion and stiffness with higher strength from the studies carried out in the specialized works [1,3,712].

PTFE thermoplastic polymeric material is frequently used in mechanical systems operating under high stress and temperature conditions. The tribomechanical properties of PTFE can be modified by the addition of fiberglass, graphite, carbon.

Thus, in this paper the materials proposed for the experiment are:

- Pure PTFE, used in various industrial applications due to its good properties related to friction and wear. It is characterized by thermal stability for temperatures between $-200 /+250^{\circ} \mathrm{C}$. The low coefficient of friction is due to the molecular structure that adheres to the metal surfaces with which it comes into contact (sliding) [1, 7, 8, 13-16].

- PTFE + fiberglass, offers much improved compression and wear properties. The percentage of fibers can vary between $5 \% . . .40 \%$ which leads to increased compressive strength, low deformation under load.

- PTFE + carbon-graphite has good mechanical and wear properties. The percentage of carbon $10 \%$...40\% added in PTFE is essential in the tribological behavior of the material.

The physical-mechanical properties of the materials under analysis are presented in Table 1.

Table 1. The physic-mechanical characteristics [17]

\begin{tabular}{|c|c|c|c|c|}
\hline Property & Units of measure & PTFE & PTFE+15\% glass & PTFE+25\% carbon graphite \\
\hline Density & $\mathrm{Kg} / \mathrm{m}^{3}$ & $2.17 .10^{3}$ & $2.20 .10^{3}$ & $2.05 .10^{3}$ \\
\hline Tensile strength & $\mathrm{MPa}$ & $30 \ldots 33$ & $20 \ldots 24$ & $10 \ldots 12$ \\
\hline Elongation & $\%$ & 300 & 260 & 60 \\
\hline Hardness & $\mathrm{Sh} . \mathrm{D}$ & 57 & 62 & 8 \\
\hline $\begin{array}{c}\text { Thermal expansion } \\
\text { coefficient }\end{array}$ & $10-5^{\circ} \mathrm{C}$ & 12 & 12 & $-170 /+260$ \\
\hline Max/min work temperature & ${ }^{\circ} \mathrm{C}$ & $-200 /+250$ & $-170 /+200$ & 65 \\
\hline
\end{tabular}

The samples were made from commercially available semi-finished products from solid rods. They were machined so that they could be mounted in the tribometer clamp.

\subsection{Theoretical considerations}

In the case of couplings with sliding motion there is generally a transfer of the polymeric material on the surface of the metallic material with which it is in contact. Once this transfer is made, the polymer / metal contact will turn into a polymer/polymer contact. The transferred polymer thus fills the "microdefects" of the mating surface by "reducing" the height of its roughness. For this situation, due to the fact that the asperities of the material are in most cases in the elastic deformation range, the wear of the coupling will be moderate.

There are situations when the transfer of material is not continuous or can break, in which case the roughness of the polymeric material can deform plastically under the action of the roughness of the metallic material. In this situation it is possible the appearance of wear particles which leads to a pronounced deterioration of the polymeric material.

In addition to material transfer, during the operation of the coupling, the polymer may undergo multiple structural changes, changes in molecular weight or changes in the orientation of the molecular chains. All these changes have a strong influence on the coefficient of friction and the wear rate. 
For any type of material coupling, the operating conditions (sliding speed, loading, temperature) have a significant effect on the coefficient of friction and wear.

In the paper for the comparative evaluation of the tribological behavior of the analyzed materials, the evolution of the coefficient of friction and the specific wear rate depending on the working parameters are established [1]:

- coefficient of friction as a ratio between the normal pressing force $F_{n}[N]$ and the frictional force $\mathrm{F}_{\mathrm{f}}[\mathrm{N}]$ :

$$
\mu=\frac{F_{n}}{F_{f}}
$$

- the specific wear rate defined as the volume of wear lost $\left(\mathrm{V}\left[\mathrm{m}^{3}\right]\right)$ for a normal load applied $\mathrm{F}_{\mathrm{n}}[\mathrm{N}]$ and the sliding distance $\mathrm{L}_{\mathrm{f}}[\mathrm{m}]$

where: $V=m / \rho$

$$
K_{s p}=\frac{V}{F_{n} \cdot L_{f}}\left[\frac{m^{3}}{N \cdot m}\right]
$$

$\mathrm{m}$-mass of material lost due to friction [kg]

$\rho$-material density $\left[\mathrm{kg} / \mathrm{m}^{3}\right]$

The analyzes were performed under equivalent operating conditions of the system and allow the comparison of different materials with each other $[1,4,5,10]$.

\subsection{Experiment conditions}

The study of the friction and wear behavior of polymeric materials in sliding contacts, showed that friction and wear are strongly influenced by operating parameters (normal load, sliding speed) $[1,7,8,15,16]$.

The experiments were performed on a pin on disc tribological friction stand [18]. The analyzed polymeric materials had the shape of a pine (cylindrical with approximately $0.8 \mathrm{~mm}^{2}$ the friction surface, and the disc was made of non-alloy construction steel SR EN 10025 from 1994. The processed surface of the disc had a roughness of Ral,6 that of the environment $20^{\circ} \mathrm{C}$. The analysis of the samples on the test stand was done under dry rubbing conditions the samples were cleaned and degreased for each experiment.

Three experiments were performed under the same conditions and their average is represented in Figures 1-6. The experiments were performed for velocities of $v_{1}=1 \mathrm{~m} / \mathrm{s}, v_{2}=3 \mathrm{~m} / \mathrm{s}$, and normal force loads of $F_{n 1}=1 N, F_{n}=3 N, F_{n 3}=5 N$ and $F_{n}=10 N$. The analysis time was 20 min for each sample. For the evaluation of wear, the method of weighing the samples was used. Thus, the samples were weighed at the beginning and end of each experiment. Knowing for each material the specific density, the volume of used material and implicitly the specific wear were calculated. The wear of the pairs of materials under analysis was assessed after the pin had traveled a friction length oo $1000 \mathrm{~m}$.

\section{Results and discussions}

The effect of slip duration on the coefficient of friction is different depending on the normal load and the sliding speed.

Figure 1 shows the evolution of the sliding friction coefficient for pure PTFE, at a sliding speed of $v_{1}=1 \mathrm{~m} / \mathrm{s}$, for the four normal forces. It is found that the values of the coefficient of friction decrease with the sliding period and with the load, after which its value stabilizes. 


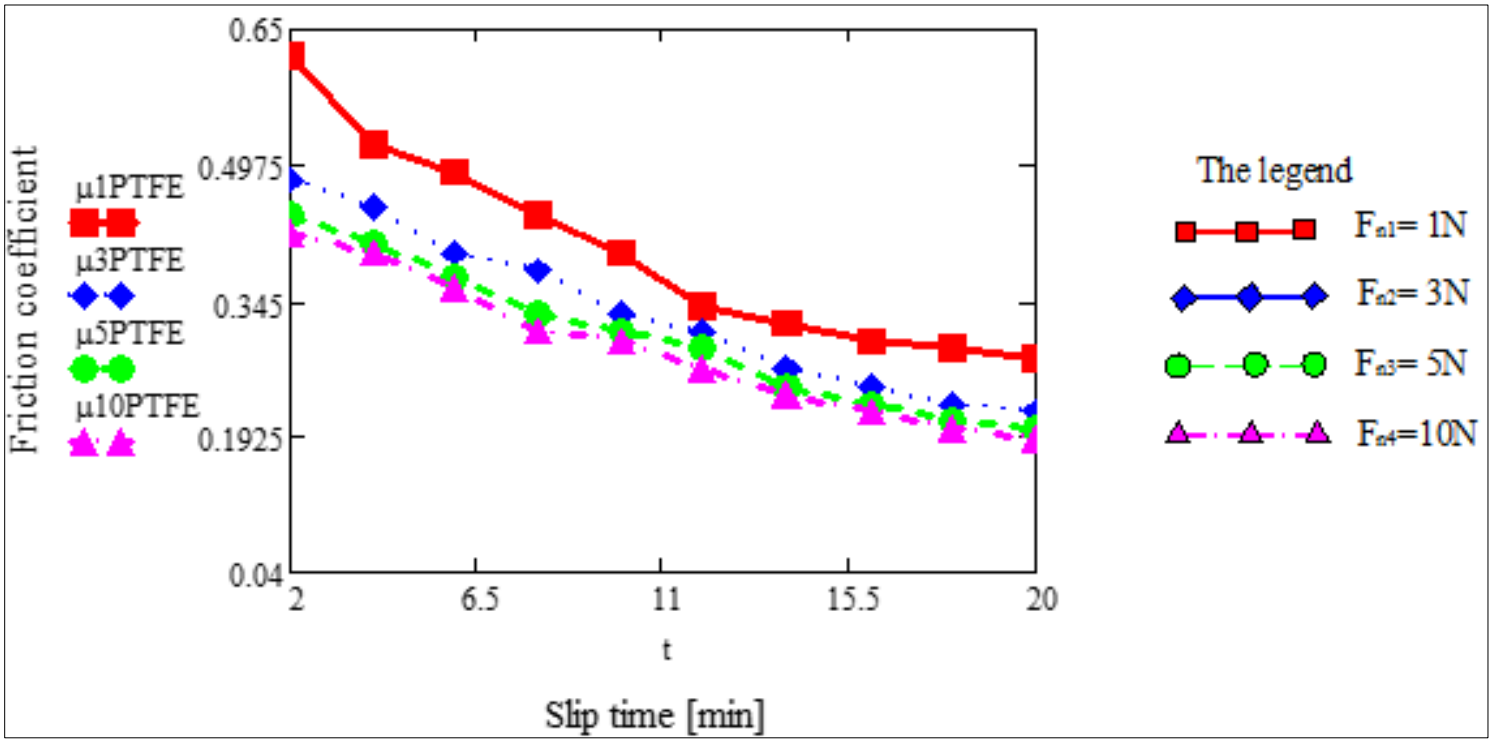

Figure 1. Variation of the coefficient of friction during sliding with the load, for a sliding speed of $v_{1}=1 \mathrm{~m} / \mathrm{s}$, for PTFE

Figure 2 shows the evolution of the sliding friction coefficient for PTFE $+15 \%$ fiberglass for a sliding speed of, for the four normal forces $v_{1}=1 \mathrm{~m} / \mathrm{s}$. An increase in the coefficient of friction is noticed in the first part of the sliding period, after which its value decreases and stabilizes. This is mainly due to the rupture of the tips of the harsh roughness of PTFE glass. The tendency of the friction coefficient to decrease with increasing load is maintained.

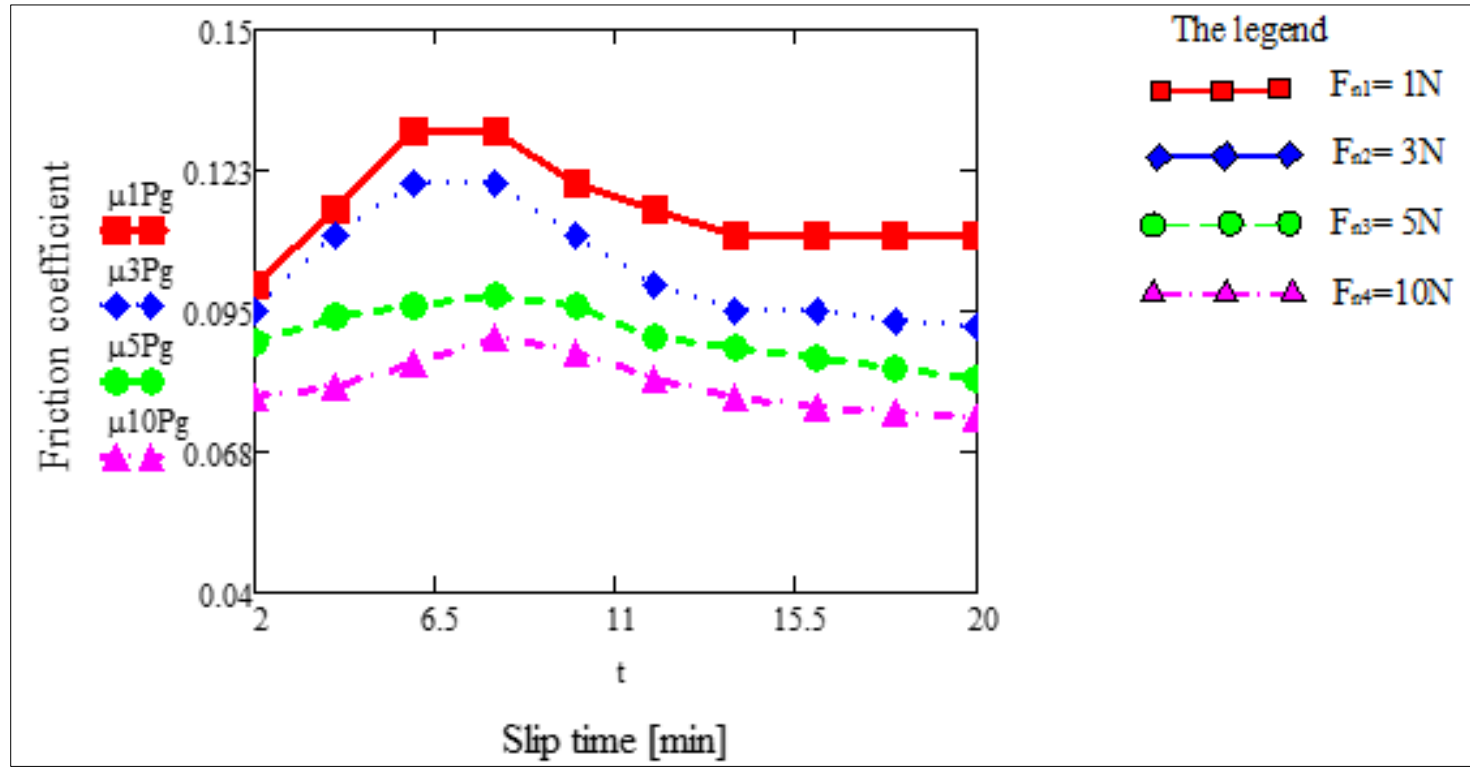

Figure 2. Variation of the coefficient of friction with the load, for a sliding speed of $v_{1}=1 \mathrm{~m} / \mathrm{s}$, for PTFE + fiberglass

Figure 3 shows the evolution of the coefficient of friction over the slip during PTFE $+25 \%$ carbongraphite, for a sliding speed of $v_{1}=1 \mathrm{~m} / \mathrm{s}$, for the four normal forces. An increase in the coefficient of friction is noticed in the first part of the sliding period, after which its value decreases and stabilizes. This is mainly due to the adhesion of carbon-graphite on the surface of the metal disc. The tendency of the friction coefficient to decrease with increasing load is maintained. 


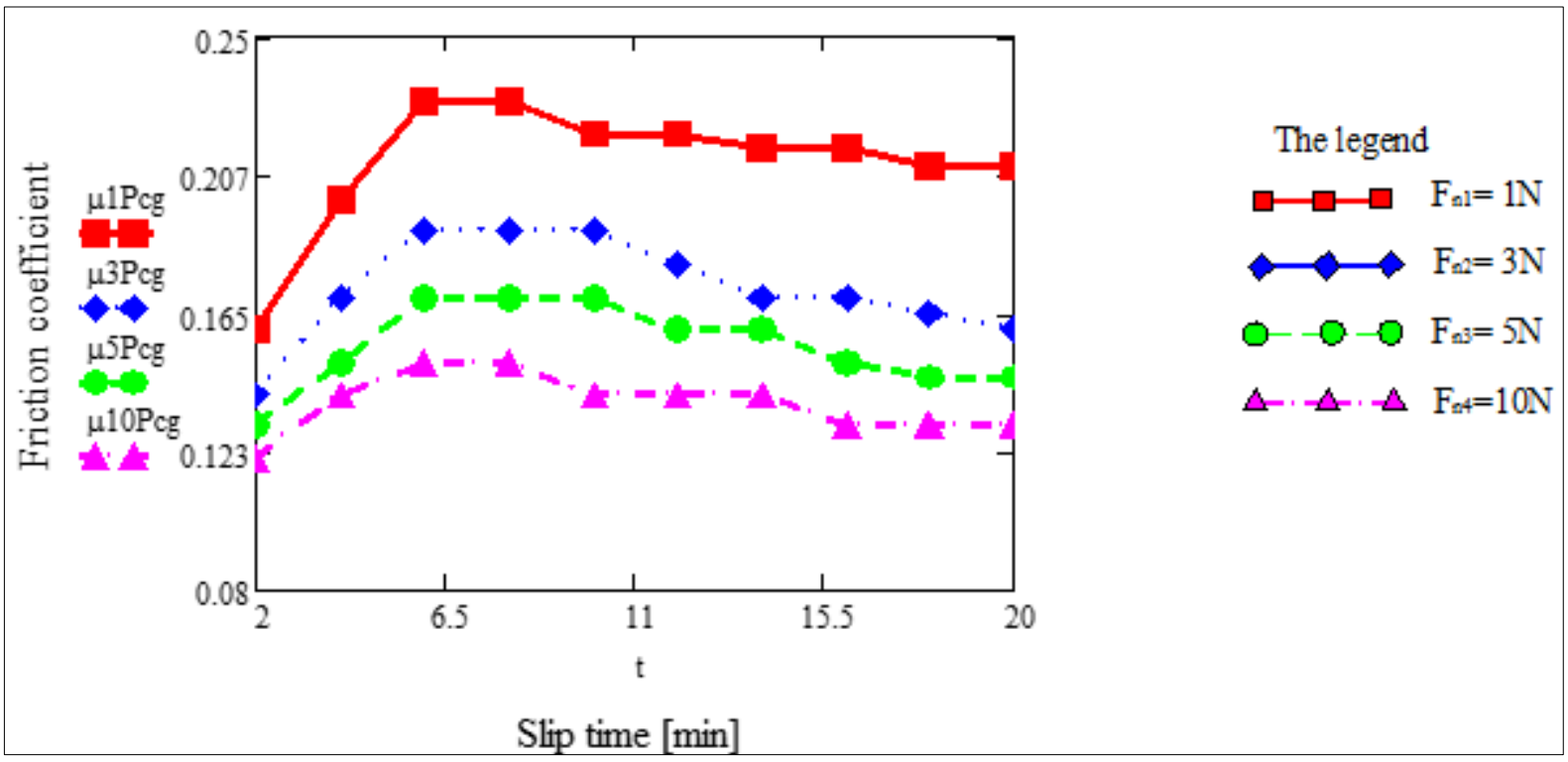

Figure 3. Variation of the coefficient of friction with the load, for a sliding speed of $v_{1}=1 \mathrm{~m} / \mathrm{s}$, for PTFE + Carbon-graphite

Figure 4 shows the evolution of the coefficient of friction for the materials under analysis for the 4 loads of the pin under different sliding speeds of the disk of $v_{1}=1 \mathrm{~m} / \mathrm{s}$, respectively $v_{2}=3 \mathrm{~m} / \mathrm{s}$.

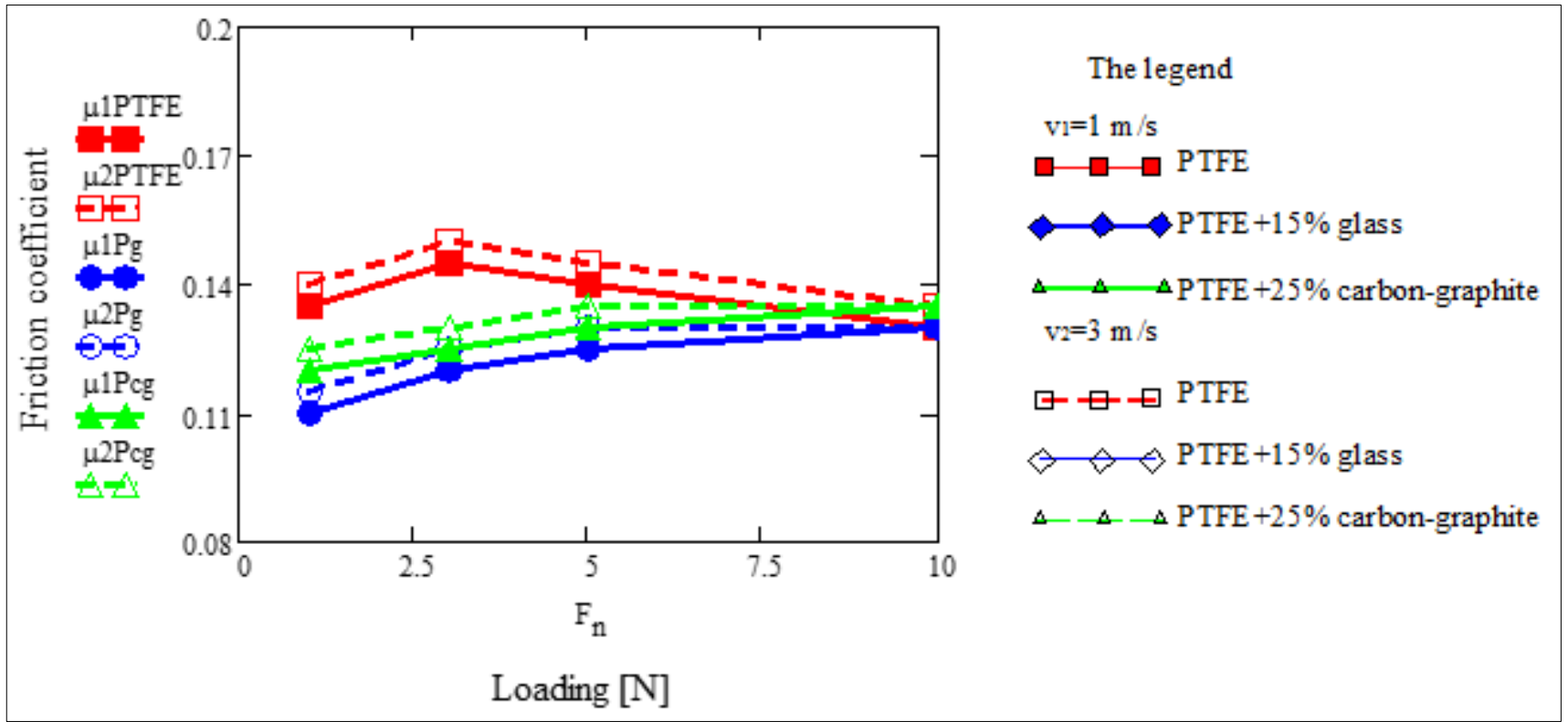

Figure 4. Variation of the coefficient of friction with the load, for the sliding speeds of $v_{1}=1 \mathrm{~m} / \mathrm{s}, v_{2}=3 \mathrm{~m} / \mathrm{s}$ for the three analyzed materials

There is an insignificant increase in the coefficient of friction for all the analyzed samples, followed by a stabilization of it. The growth trend is due to the adhesion of the polymeric material on the surface of the disc.

Figure 5 shows the evolution of the coefficient of friction as a function of the sliding speed for loads of the pin of $F_{n 1}=1 N$ and $F_{n}=10 N$. It is worth noting the insignificant increase of the coefficient of friction with the sliding speed at different loads. 
Figure 6 shows the evolution of the wear rate of the analyzed samples as a function of the increase of the normal load $\left(F_{n 1}=1 N, F_{n 2}=3 N, F_{n 3}=5 N\right.$ and $\left.F_{n 4}=10 N\right)$ for a friction length of $1000 m$. The additives introduced in PTFE, give it a better wear behavior. The PTFE material $+15 \%$ fiberglass compared to the other materials analyzed has a lower wear rate.

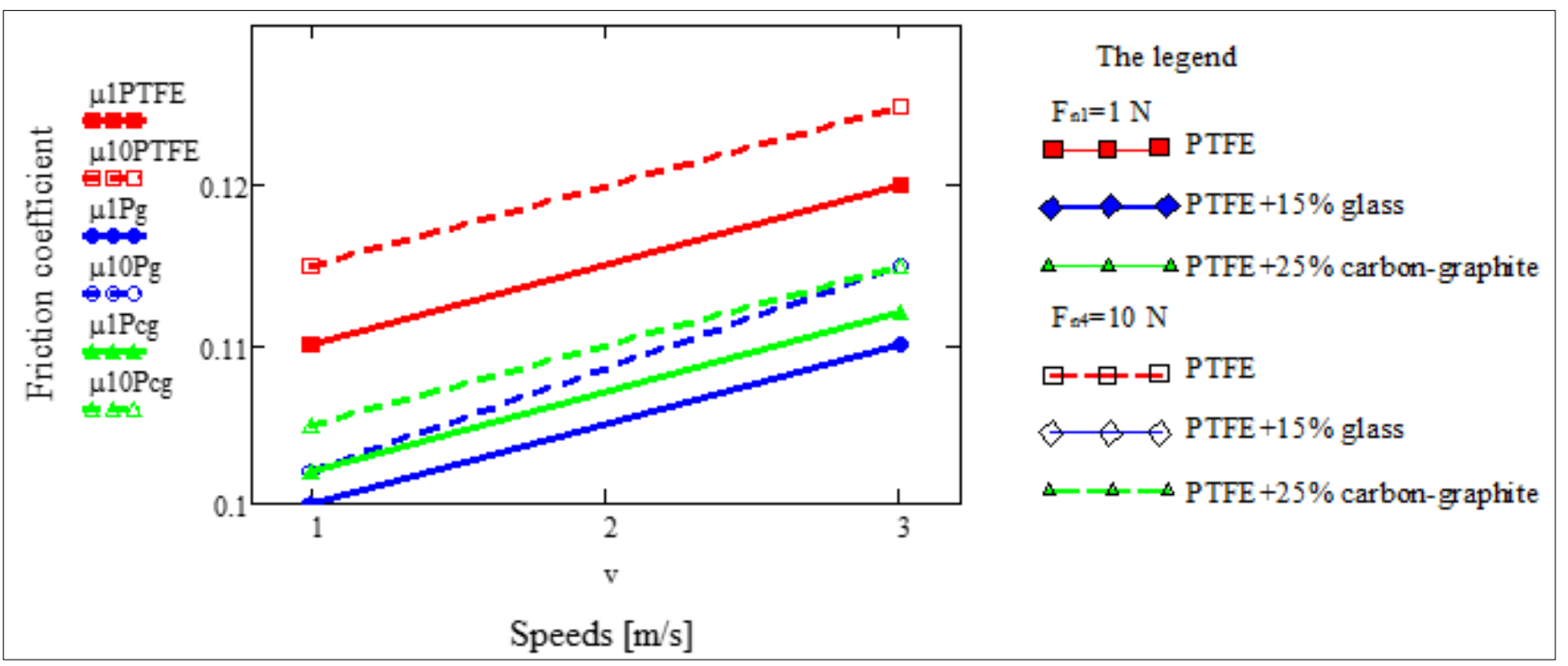

Figure 5. Variation of the coefficient of friction as a function of sliding speed, for a load of $F_{n 1}=1 \mathrm{~N}$ respectively $F_{n}=10 \mathrm{~N}$, for the analyzed materials

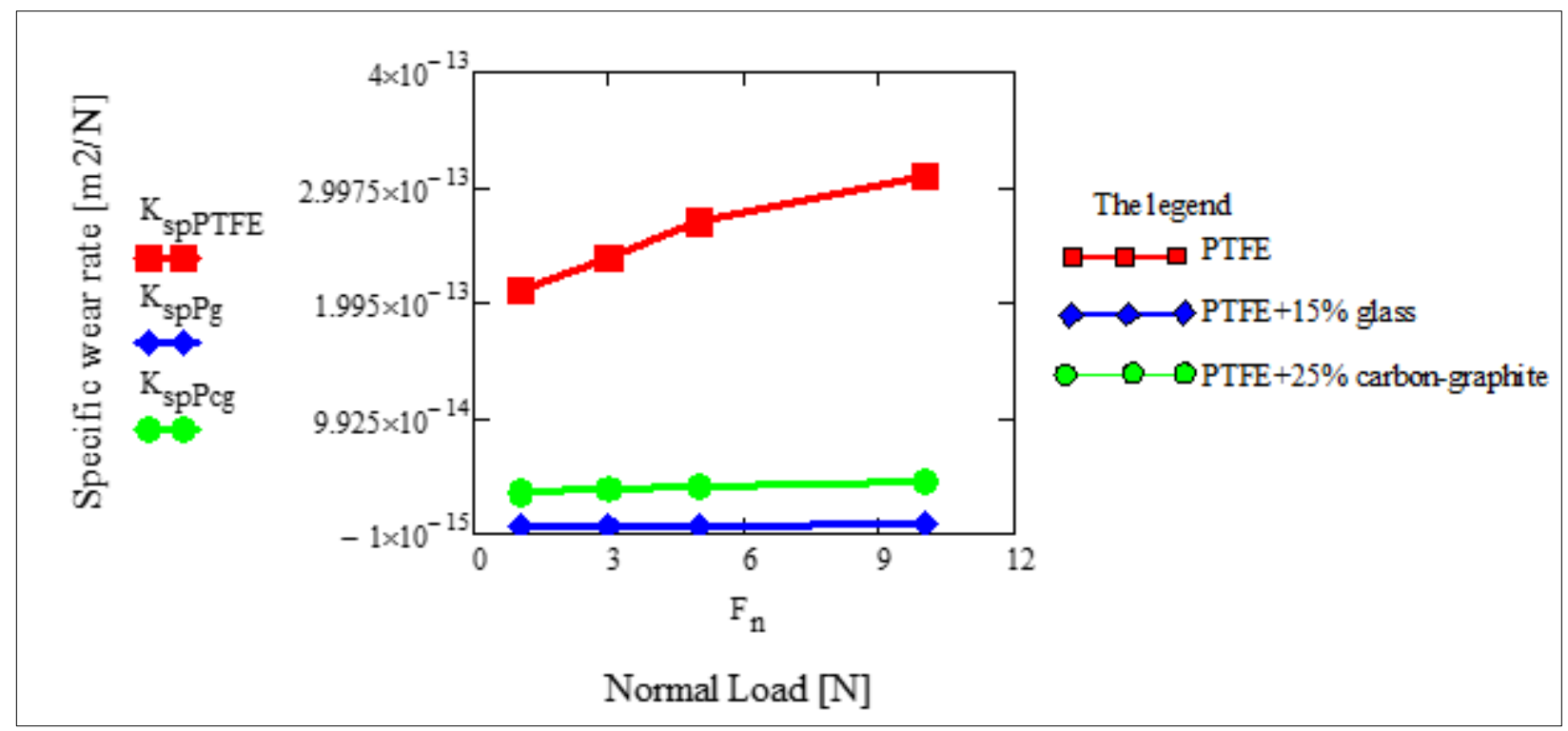

Figure 6. Variation in weight loss with load for the three materials

Figure 7 shows microscopic images [19] of the contact area in the sliding direction (from left to right) for the improved PTFE structure for different operating conditions [15, 19]:

a) PTFE $+15 \%$ fiberglass, $\mathrm{p}=3.0 \mathrm{MPa}, \mathrm{v}=1 \mathrm{~m} / \mathrm{s}$;

b) PTFE $+23 \%$ carbon $+2 \%$ graphite $\mathrm{v}=3 \mathrm{~m} / \mathrm{s}$ and $\mathrm{p}=5 \mathrm{MPa}$;

It stands out in the Figure 7a the orientation of the glass particles in the direction of sliding. Figure $7 b$, represents the orientation of graphite carbon (white area) with the sliding direction. 


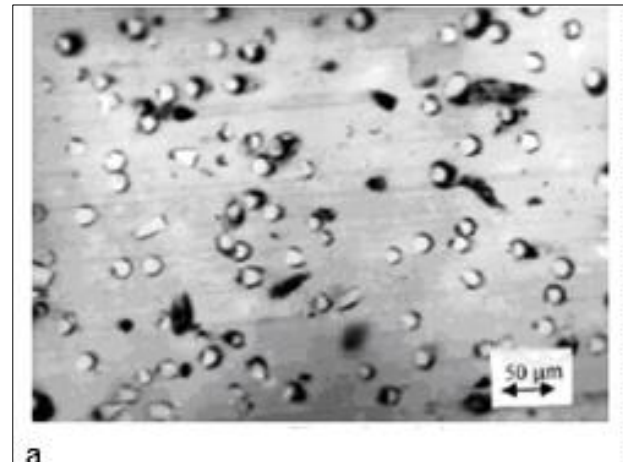

a

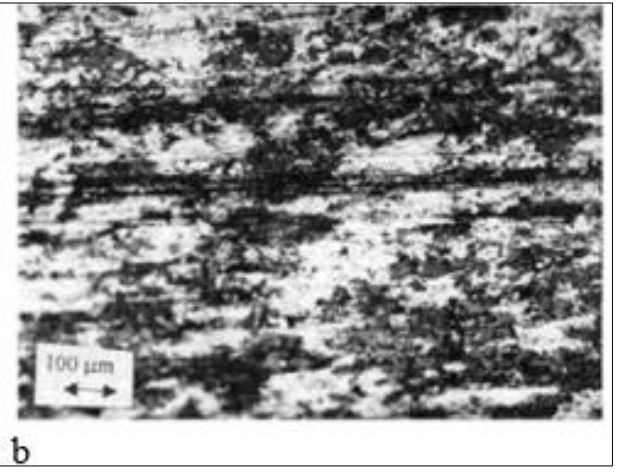

Figure 7. Improved PTFE sliding contact area microscopes [19]

The results obtained experimentally correspond to many researchers found in specialized journals $[1,2,7,8,10-14,20]$.

\section{Conclusions}

The main purpose of this paper is to presents a comparative study, on a pin / disc type friction stand, of the friction and wear properties of pure polytetrafluoroethylene (PTFE), fiberglass-reinforced PTFE, and $25 \%$ carbon-graphite reinforced PTFE sliding on a surface of the steel, in conditions of dry friction.

The evaluation of the size of the coefficient of friction and wear with working parameters is one of the aspects of interest in this field. It was sought that the experimental conditions be as close as possible to the industrial exploitation conditions so that there is a more realistic picture of the tribological behavior of these materials.

Following the experimental studies performed, the following conclusions can be drawn:

- the additions introduced in the basic PTFE material give it superior friction and wear qualities;

- the normal load applied to the pin influences both the coefficient of friction and the degree of wear of the material coupling;

- for pure PTFE the increase in load visibly leads to an increase in wear, while for PTFE improved with fiberglass or carbon-graphite this increase is very small;

- the coefficient of friction may be changed depending on the operating parameters and the ingredients introduced into the base material;

- the load applied to the pin has a greater effect on the friction than the speed for the analyzed materials;

- the experimental results indicate that PTFE $+15 \%$ fiberglass has a better wear behavior than pure PTFE or PTFE + carbon-graphite;

- the weight loss of each material increased with the increase of the sliding and loading distance of the pine;

- a small value of the coefficient of friction does not necessarily mean a small wear;

- the behavior of any material coupling is strongly influenced by the working parameters (load, sliding speed, sliding distance).

The tribological performance of the materials under study showed that of the three PTFE-based materials, the PTFE composite reinforced with $15 \%$ glass fibers showed good tribological performance. It under similar test conditions has a low coefficient of friction and high wear resistance, compared to pure PTFE polymer and PTFE composite with 25\% Carbon-graphite.

The wear rate for PTFE reinforced with $15 \%$ fiberglass was of the order compared to pure PTFE which had a wear rate of the order. The wear rate obtained under the experimental conditions for the three materials falls within the limits found in the literature $[1,12,14]$.

The results of this research can be used in practice to design high-performance mechanical systems, in order to improve the various mechanical processes in which friction phenomena occur. 


\section{References}

1. UNAL H., YETGIN S.H., MIMAROGLU A., SUMER M., The Effect of Test Parameters on Friction and Wear Performance of PTFE and PTFE Composites, Journal of Reinforced Plastics and Composites, 29(13), 2009, 1978-1986.

2. RUS D., CAPITANU L., BADITA L.L., A qualitative correlation between friction coefficient and steel surface wear in linear dry sliding contact to polymers with SGF, Friction, 2(1), 2014, 47-57.

3. BHUSHAN, B. Introduction to tribology, Second edition, A John Wiley\& Sons, Ltd., Publication (2013).

4.JEBRAN KHAN, M., WANI, M.F., GUPTA, R., Friction and wear characterization of graphite/ Polytetrafluoroethylene composites against stainless steel: A comparative investigation under different environments, IOP Conf. Series: Journal of Physics: Conf. Series 1240 (2019) 012107, 1-8.

5.PETRE I., ENESCU M. C., STOIAN E. V., Research Regarding the Evolution of Friction Coefficient in a Friction Torque Like a Plastic Material / Steel for Different Parameters, Mater. Plast., 56(4), 2019, 918-922.

6.PETRE I, POPESCU I.N., UNGUREANU D. N., Aspects regarding the tribological behavior of Turcite and Relamid polymeric materials, in sliding motion couples, Mater. Plast., 56(1), 2019, 55-58.

7.CHEN, J., JIA, J., ZHOU, H., CHEN, J., YANG, S., LIN FAN, L. (2008). Tribological Behavior of Shortfiber- reinforced Polyimide Composites under Dry-sliding and Water-lubricated Conditions, Journal of Applied Polymer Science, 107: 788-796.

8.KOWANDYA, C., RICHARDA, C., CHEN, Y. M. (2008). Characterization of Wear Particles for Comprehension of Wear Mechanisms Case of PTFE against Cast Iron, Wear, 265: 1714-1719

9.TABOR, D. Friction, Lubrication and wear, W Source: Mechanical design handbook (2003).

10.FRIEDRICH, K., Polymer composites for tribological applications, Advanced Industrial and Engineering Polymer Research, 1 (1), 2018, 3-39.

11.WANG, Q., XUE, Q., LIU, W., CHEN, J., The friction and wear characteristics of nanometer SiC and polytetrafluoroethylene filled polyetheretherketone, Wear, 2000, 243, 140-146.

12.BAHADUR, S., POLINENI, V. K., Tribological studies of glass fabric-reinforced polyamide composites filled with $\mathrm{CuO}$ and PTFE, Wear, 1996, 200, 95-104.

13.DE BAETS P., Comparison of the wear behavior of six bearing materials for a heavily loaded sliding system in seawater, Wear, vol. 180, pp. 61-72, 1995.

14.EL-SAYED A. A., EL-SHERBINY M.G., ABO-EL-EZZ A.S., AGGAG G.A., Friction and wear properties of polymeric composite materials for bearing applications, Wear, vol. 184, pp. 45-53, 1995.

15.DELEANU, L., BIRSAN, IG., ANDREI, G., PTFE composites and water lubrication - Tragicalcharacterization. Mater. Plast., 44(1), 2007, p. 66.

16.LV, Y., WANG, W., XIE, G., LUO, J., Self-Lubricating PTFE-Based Composites with Black Phosphorus Nanosheets, Tribol Lett 66, 61 (2018). https://doi.org/10.1007/s11249-018-1010-5.

17. ***https://www.ptfe.ro/produse/teflon

18. PETRE, I.C., CATANGIU, A., POPESCU, I.N., UNGUREANU, D. N., NEGREA, A., POINESCU, A.A., ENESCU, M.C., STOIAN, E.V., DESPA, V. Tribometric device for determining friction forces and friction coefficients in the case of dry friction materials, The Scientific Bulletin of Valahia University, Materials and Mechanics, 16(15), 2018, 17-20.

19. ŞTEFĂNESCU, I., DELEANU, L., RÎPĂ, M., Lubrifiere și lubrifianți, Editura EUROPLUS, Galati 2008.

20. BASTIUREA, M., DIMA, D., ANDREI, G., Effect of Graphene Oxide and Graphite on Dry Sliding Wear Behavior of Polyester Composites, Mater. Plast., 55(1), 2018,102-110.

Manuscript received: 11.10.2019 